\title{
A Feasibility Study on the Design, Development and Operation of an Automated Oceanic Wave Surface Glider Robot
}

\author{
Yao Wang a Amir M. Anvar a , Amir Parsa Anvar a , Eric Hu ${ }^{\text {a }}$ \\ ${ }^{a}$ School of Mechanical Engineering, \\ Faculty of Engineering, Computer, and Mathematical Science, \\ The University of Adelaide, \\ Adelaide, South Australia, 5005 \\ AUSTRALIA \\ Emails:yao.wang@student.adelaide.edu.au ; amir.anvar@adelaide.edu.au
}

\begin{abstract}
As oceanic research continues to grow for scientific and commercial purposes, demand for knowledge pertaining to the ocean continues to increase. This research investigates a Wave Glider that was developed by engineers for the purpose of collecting data from oceans. The Wave Glider is a novel two-body unmanned surface vehicle (USV). Compared to traditional unmanned surface vehicles, the Wave Glider has the unique advantage of long term navigation ability. With this advantage, the vehicle can complete missions which require long-term ocean trials.
\end{abstract}

This research project is focused on studying the feasibility of improving the design and operation of the Wave Glider and further developing its capabilities. To obtain real-time data, a scale model based on the original Wave Glider design has been manufactured. Improvement to the original design has already been achieved with regards to improving the stability of the wings. Based on a literature review, some concern was found over its robustness when trialing and this is addressed in this paper. Throughout this research, Computational Fluid Dynamics (CFD) analysis has been done on the Wave Glider to ensure optimum efficiency. Furthermore, CAD design of the scaled model has been reviewed to ensure success in manufacturing and operation. The Wave Glider model will be used to collect real time data for comparison with simulated data. Additional improvements included in the model will also be discussed.

Keywords: Ocean, Wave, Surface, Glider Robot, Modeling, Numerical, Simulation, Automated, Optimise, Control 
Yao Wang, Amir M. Anvar, Amir Parsa Anvar, Eric Hu; A Feasibility Study on Design, Development and Operations of Automated Oceanic Wave Surface Glider Robot

\section{INTRODUCTION}

As the ocean accounts for more than $70 \%$ of the surface area of the earth, numerous research projects are being undertaken on this increasingly important human resource. Much of this research is dependent on acquisition of data from the ocean. However, the aquisition of data is often expensive and its collection can be dangerous if done by humans. As a solution to this problem, different types of Unmanned Surface Vehicles (USV) have been invented to aid humans in meeting the demand for obtaining data from the ocean. Nevertheless, most USVs suffer from lack of power while trailing (Manley 2008). As a result, the trial distance is limited by the power source on board. As the sizes of USVs are generally small, the power source onboard is usually insufficient to accomplish missions with long time trials (Daniel, Manley \& Trenaman 2011). In order to solve this problem, the Wave Glider has been developed, which demonstrates a new USV platform with unique capabilities for continuous data collection, in a complex marine environment.

The innovator of the Wave Glider, Roger Hine, started to work on a prototype in 2005. His main objective was to create a new type of USV, which could operate with no costly deep water mooring or shipping operations. The final design is a hybrid sea surface and underwater vehicle consisting of a submerged glider, attached via a tether, to a surface float (Manley and Willcox 2010). The vehicle is propelled by the submerged glider which can convert the vertical ocean wave motion energy into forward thrust. All other electrical devices are powered by solar panels attached to the float. Ion-lithium batteries are attached to the solar panels for power storage. As this vehicle was designed specifically to collect data from the ocean, the vehicle is capable of accommodating various kinds of sensors which may be used for different applications during missions (Hine et al. 2009). In 2010, the vehicle was tested and operated in the ocean for 600 days, which exceeded the original target of 1 year. Therefore the design has proven to be a successful platform for the purpose of long term trials (Daniel, Manley \& Trenaman 2011).

The objective of the current project is to further develop the Wave Glider in terms of design and features. In order to obtain more data from the Wave Glider during operation, a scaled prototype has been designed and manufactured for further study in this research project. As part of this process, the entire propulsion system was analysed. This analysis formed the basis for improving the propulsion system and the vehicle's stability.

\section{THE ORIGINAL WAVE GLIDER ROBOT}

\subsection{Original Structure \& Working principal}

A Wave Glider was designed with hybrid sea-surface float and submerged propulsion systems, connected by an umbilical (tethered) cored. The breakdown of its structure is illustrated in Figure 1. While operating, the vertical wave energy captured by the float will translate to the submerged glider through a tether, and directly turn into forward motion (Daniel, Manley \& Trenaman 2011). Surface waves pull the submerged glider, while the float is passing through a wave crest. The wings turn to a certain angle, due to the inertia of the water, while the submerged glider is pulled up and down. Because of this angle, the glider's wings convert wave-powered vertical motion into forward motion.

The wave energy propulsion system is powered purely by mechanical energy, which means that there will be no electrical power supplying the submerged part in terms of forward motion. This propulsion system is effective, since there is no energy lost from conversion. Therefore, the total energy lost, as a result of converting renewable energy into another form of secondary energy, can be eliminated. However, according to the data provided for Wave Glider, the maximum speed of the vehicle is only 2.25 knots, which is dominated by the magnitude of the wave (Hine et al. 2009). In this case, the Wave Glider is only suitable for missions with a long trial time. If the

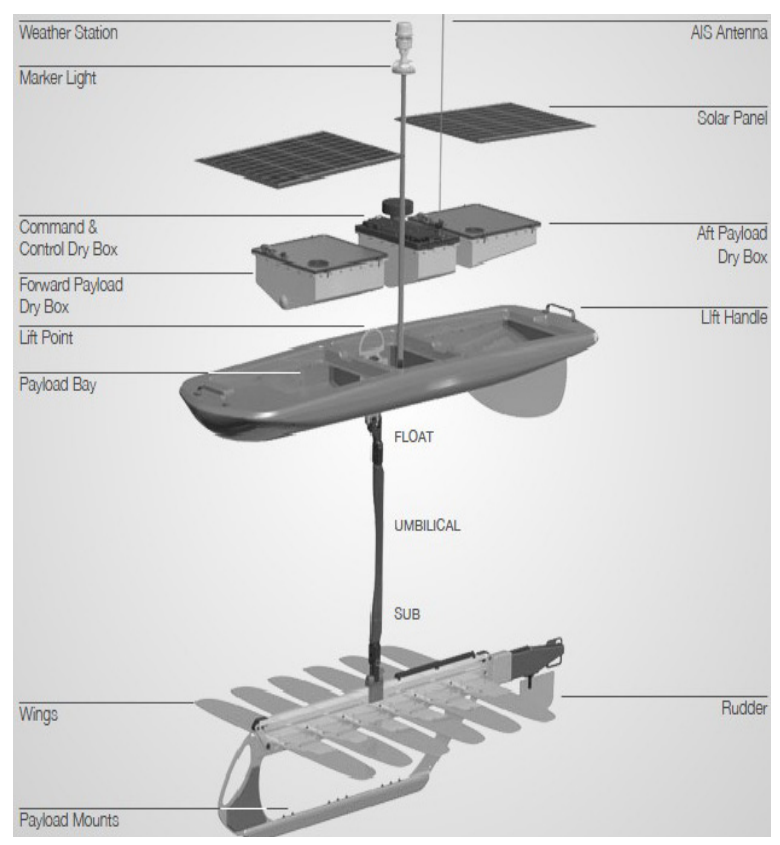

Figure 1. Breakdown of Wave Glider Structure (Liquid Robotics Inc. 2009) 
Yao Wang, Amir M. Anvar, Amir Parsa Anvar, Eric Hu; A Feasibility Study on Design, Development and Operations of Automated Oceanic Wave Surface Glider Robot

mission consisted of a quick trial with a time limitation, the glider may not be able to complete it.

The magnitude of motion caused by propulsion is dominated by the difference between two wave crests. In this case, sea state is introduced as a parameter describing the general wave magnitude. Table 1 presents data which has been collected by Hine et al. (2009) regarding the relationship between sea state and the general speed of the Wave Glider.

It can be shown that the Wave Glider's speed is proportional to sea state. However, it is not known, whether the direction of a high speed wave will influence the direction of the Wave Glider. Despite that, it has been demonstrated by the designer that the Wave Glider can trail, independent of wave direction. However it can be predicted that the direction will be influenced by the wave direction, during a high sea state.

\subsection{Operation in High Sea State}

The Wave Glider can survive extreme sea conditions. Basically, the Wave Glider's mechanical endurance is only limited by its robustness. As expected, in 2007, the Wave Glider was capable of navigating in weather conditions associated with $10+$ foot tides and $40+$ knot winds. This proved its mechanical stability. As the sea state increases, the energy consumed in the waves will keep rising. This leads to the buoyancy generated by the float being neutralized by the vertical drag force generated by the inertia of the submerged glider in the water. This causes the surface float to dive into the larger tides (Hine et al. 2009). This phenomenon occurs when the energy consumption of the waves exceeds the Wave Glider's energy capturing capacity. This phenomenon tends to protect the structure from damage by the waves, since the wave energy is reduced below the water surface and continues to decrease as the depth increases. Hence, the Wave Glider can be protected under the high sea state situation. A larger model can be generated for capturing more energy from the waves during a high sea state. When considering the possibility of working under the high sea state, improvement on designs could increase this effectiveness by reinforcing the wings.

\section{SEA CONDITION IN SOUTH AUSTRALIA}

By considering the sea condition of South Australia, the speed of Wave Glider can be predicted if it is deployed in the sea area of South Australia. The graph of wave height for the sea near Kangaroo Island in SA, which has been obtained by the Bureau of Meteorology, is illustrated in Figure 2. It can be seen that the general wave height, varies from $4.7 \mathrm{~m}$ to $0.8 \mathrm{~m}$. This can be used to carry out the sea state around South Australia using the Douglas Sea Scale, which is from 3 to 6 . Referring to Table 1, the speed of the Wave Glider if it is deployed in the sea around South Australia is generally higher than 2.25 kts.

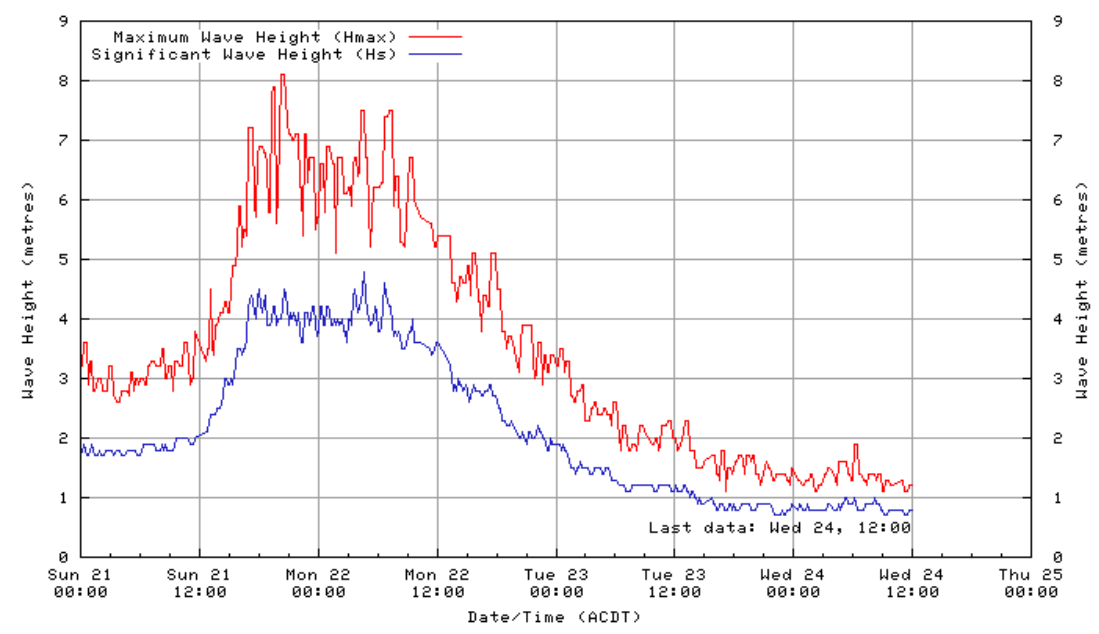

Figure.2. Graph with Significant Wave Height \& Maximum Wave Height of SA (Bureau of Meteorology) 
Yao Wang, Amir M. Anvar, Amir Parsa Anvar, Eric Hu; A Feasibility Study on Design, Development and Operations of Automated Oceanic Wave Surface Glider Robot

\section{DESIGN FEATURE}

\subsection{Submerged Glider}

In order to convert the vertical wave motion into forward thrust, the wings should be able to rotate up and down through a certain angle range, according to the horizontal level. The same device is applied in the miniature model. In addition, for the purpose of increasing the reliability of the structure, the diameter of the shafts has been increased and Vesconite bearing material has been used to cover the shafts to protect them from damage while continuously turning. Considering that the sea state of South Australia is relatively high compared with many sea regions, reinforcement of the wings is considered necessary for the Wave Glider to ensure that it will not fail. While operating, the submerged glider is pulled up and down by the buoyancy force of the float and the gravity force respectively. Since the gravity force is relatively constant and mild, compared with the buoyancy force, the structure is more likely to be

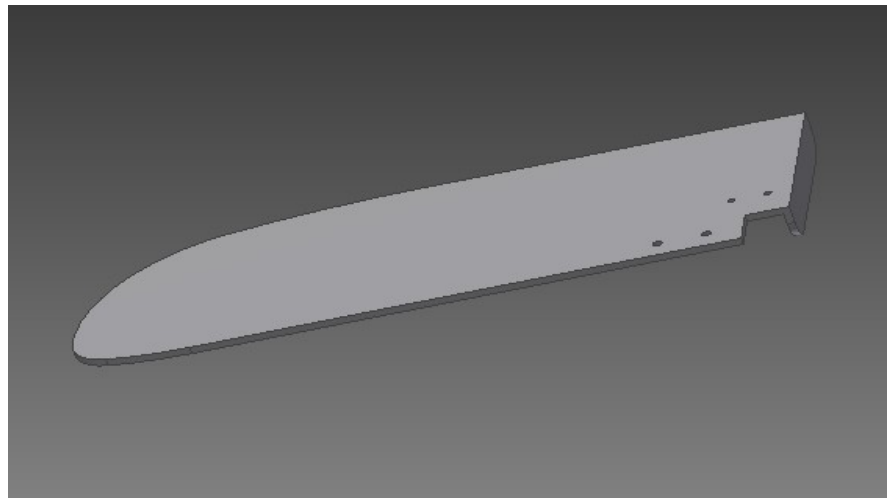

Figure.3. Optimized wing Reinforcement

TABLE 2. Results OF FEA SIMULATION

\begin{tabular}{|c|c|c|c|c|}
\hline \multirow{2}{*}{} & \multicolumn{2}{|c|}{ Original Wing } & \multicolumn{2}{c|}{ Designed Wing } \\
\cline { 2 - 5 } & Max & Min & Max & Min \\
\hline Stress (MPa) & 20.14 & 0 & 15.32 & 0 \\
\hline Displacement $(\mathrm{mm})$ & 0.8643 & 0 & 1.054 & 0 \\
\hline Strain (mm/mm) & $2.713 e$ & $\begin{array}{c}2.75 e- \\
008\end{array}$ & $\begin{array}{c}2.021 e- \\
004\end{array}$ & $\begin{array}{c}7.195 e- \\
009\end{array}$ \\
\hline
\end{tabular}
damaged during the pulling up phase, compared with the gravity force dominated phase. Therefore, the wings require reinforcement to resist the drag force generated, while being pulled up. The new folded-end wing has been designed and tested using the FEA method. This design aims to reinforce the wings, while the submerged glider is pulled up by the float. Figure 3 shows the 3D drawing of the optimized wing design.

In order to obtain a quantification of the improvement and examine the stability, a simple Finite Element Analysis (FEA) simulation has been carried out. The result shows that less stress occurs in the reinforced wing while it is under downward drag force, when compared with the original design. This difference is not large, since the structure of this design is much smaller than that of the original Wave Glider. It can be predicted that the result of the larger size can be more significant than that of this miniaturised model. However, for ease of manufacture, some parts have been designed with simplification. The system still functions normally, since the principals remain the same as with the original design.

\subsection{Float}

The material selected for the float is hard foam, which provides both mechanical stability and buoyancy. In the design of the underwater float, the primary property is buoyancy. It must be able to provide sufficient buoyancy, lifting the submerged glider as well as the onboard dry boxes. The total weight of the submerged glider has been calculated to be $6.99 \mathrm{~kg}$. In this case, the buoyancy provided by the float should be at least 7 $\mathrm{kg}$, to lift the glider individually. However, in reality, the weight of electrical devices and a safety factor should also be taken into consideration. Since two solar panels have been installed on the float, the weight added by the panels is $3 \mathrm{~kg}$. By considering the safety factor and the weight of other electrical devices, the total buoyancy generated by the float is $20 \mathrm{~kg}$. It can be calculated, by using buoyancy formula, that the volume of the float must be at least $0.06 \mathrm{~m}^{3}$. The calculation is shown below.

Total weight $=$ Weight of Submerged Glider + Weight of Onboard Devices $=7 \mathrm{~kg}+3 \mathrm{~kg}=10 \mathrm{~kg}$

Given a safety factor of 2

Total weight $=20 \mathrm{~kg}$ 
Yao Wang, Amir M. Anvar, Amir Parsa Anvar, Eric Hu; A Feasibility Study on Design, Development and Operations of Automated Oceanic Wave Surface Glider Robot

Bouyancy $=\rho_{\text {water }} * g * V_{\text {underwater }}$

It is assumed that $\mathrm{V}_{\text {underwater }}$ is the total volume of the float.

Bouyancy $=20 \mathrm{~kg} * \mathrm{~g}=1000 \mathrm{~kg} / \mathrm{m}^{3} * \mathrm{~g} * \mathrm{~V}_{\text {underwater }}$

$\mathrm{V}_{\text {underwater }}=0.02 \mathrm{~m}^{3}$

Thus, the float's size has to be larger than $0.02 \mathrm{~m}^{3}$ to provide sufficient bouyancy to lift the entire vehicle.

The actual volume of the float is $0.06 \mathrm{~m}^{3}$. Thus, the modified Wave Glider will be buoyant. In order to achieve those features, the material selected for the float is closed cell foam. Closed cell foam is a low water absorption material. It can maintain buoyancy for a long time in a marine environment. The closed cell foam selected for this project, has a $0.7 \%$ water absorption ability, which means that there will be minimal buoyancy reduction while trailing in the sea, for a long time.

The float is composed of two payload dry boxes; one in the front side and another in the back. Moreover, it also comprises two solar panels, which are used to charge the batteries. The dry boxes are the containers for the onboard electrical devices. They should be waterproof and made stable inside of the float.

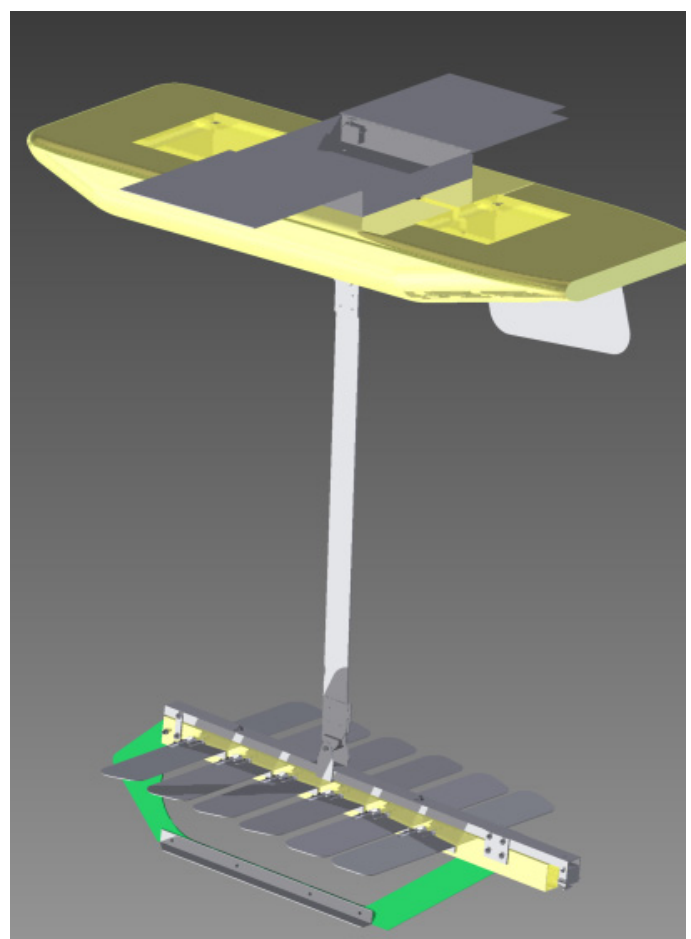

Figure 4. Final Design of Wave Glider

Compared with the original float design, a landing and charging station for the maritime quadrotor unmanned air vehicle (UAV), as a new feature, has been included on the middle of the float. Although the Wave Glider is a suitable USV for collecting data from the ocean; the slow trailing moving speed is a weakness. With this new feature, a quadrotor UAV can be stored inside the landing station. When the Wave Glider is approaching the target, it can release the quadrotor UAV robot by opening the landing station. The quadrotor can investigate the target ahead of the Wave Glider. Moreover, the quadrotor UAV can detect potential dangers before the Wave Glider moves into them. As the quadrotor is not a constantly trailing robot, the electrical power is only required for the short periods when it is working away from its landing station. Future work will include the design and incorporation of a recharging device to charge the quadrotor by using the electrical power generated by the solar panels. In this way, the quadrotor and Wave Glider can be combined.

For control, a Freetronics control kit has been selected for the control system. This board is suitable for both communication and control. The board is able to act as the microcontroller for the servo motor, which is contained in the back of the submerged glider. When instruction(s) is sent from the computer, the controller sends a signal to the servo motor to turn the rudder to the desired angle and control the direction of the Wave Glider. Moreover, the board has the flexibility to control and acquire data from many sensors.

\section{CFD SIMULATIONS FOR VALIDATION}

The aim of this simulation is to determine the fluid behaviour around the wings of the Wave Glider and analyse the speed of stream lines. Since the speed is generated by wave power, the speed of the streamlines in this CFD project can be considered to be the same as the speed of the wave glider. In this way, the simplified model of the Wave Glider is generated. Since the wings are the points of interest for this simulation, and for ease of simulation, they are the only features which have been taken into account for modelling. Validation is achieved by comparing the experimental data and the simulation results.

\subsection{Generic Governing Equation}

In this project, the model is generated in $3 \mathrm{D}$ and operating in water which is an incompressible substance. For ease of simulation, we assume that the flow is steady. Thus, the continuity equation and momentum equation can be generated as shown below: 
Yao Wang, Amir M. Anvar, Amir Parsa Anvar, Eric Hu; A Feasibility Study on Design, Development and Operations of Automated Oceanic Wave Surface Glider Robot

Continuity equation

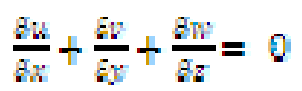

Momentum equation

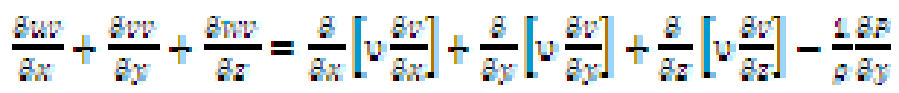

In this simulation, the assumption is made that the wave only generates vertical motion. Horizontal motions of the fluid in the ocean are too complex and difficult to simulate and have therefore been disregarded.

\subsection{CFD Results and Validation}

As previously stated, the speed of the Wave Glider regarding sea state in South Australia is greater than 2.25 kts or $1.15 \mathrm{~m} \cdot \mathrm{sec}^{-1}$.

In comparison, the forward speed obtained from the CFD simulation is $1.6 \mathrm{~m} . \mathrm{sec}^{-1}$ as the wave power is dominating the Wave Glider. There is some difference between experimental data and the simulation results. The major reason for this difference is a result of the simulation only calculating the result for the situation where the wave pulls up the Wave Glider. In this situation, the fluid speed can be much faster than the speed when the Wave Glider is going downwards. This results in the forward speed of the wave glider, when going up, to be much faster than when it is going down. Thus, the result from the simulation is slightly larger than that of the real data. To achieve a more accurate simulation result, another simulation of the Wave Glider, going downwards, has been undertaken. The forward speed for this scenario was calculated to be 0.15 $\mathrm{m} \cdot \mathrm{sec}^{-1}$. The overall speed calculated by

\begin{tabular}{|c|c|c|}
\hline$\sigma$ & Downwards & Upwards \\
\hline $\begin{array}{c}\text { Stream line } \\
\text { speed }\left(\mathrm{m} \cdot \mathrm{sec}^{-1}\right)\end{array}$ & 0.15 & 1.6 \\
\hline
\end{tabular}

Table 3. CFD Simulation Results averaging the fluid speed for both the "upward" and "downward" progression phases is 0.875 m.sec ${ }^{-1}$ which is similar to the experimental data of $1.15 \mathrm{~m} \cdot \mathrm{sec}^{-1}$.

\section{CONCLUSION}

The wing design and CFD simulation of the Wave Glider have been analysed for the sea conditions in South Australia. The optimisation of the wing design of the Wave Glider has been carried out. The optimized wing has been incorporated into the design of a scale model of the Wing Glider. The manufacturing drawings of the relative parts have been generated and the manufacture of the Wave Glider test-bed is fulfilled.

The Wave Glider model is a novel USV and further research and development will improve the control system and mechanical devices. This could involve improving the electrical system design, the energy management system and the structural design. Moreover, further investigation should be undertaken into the feasibility of integrating the quadrotor UAV robot into the float. This would lead to improvements in the endurance, control and speed of the USV.

\section{ACKNOWLEDGMENTS}

The authors would like to acknowledge Ian Brown for his editorial comments, remarks and feedback on this paper. The support from Defence Science and Technology Organisation (DSTO) during the course of the Project is also acknowledged. A special thanks goes to the University of Adelaide and its Mechanical and Electronics workshop staff for the manufacturing support and provided equipment.

\section{REFERENCES}

Daniel, T, Manley, J \& Trenaman, N. (2011). "The Wave Glider: enabling a new approach to persistent ocean observation and research." Ocean Dynamics 61(10): 1509-1520.

Hine, G, Hine, R, Willcox, S \& Richardson, T. (2009). The wave glider: A wave-powered autonomous marine vehicle. OCEANS 2009, MTS/IEEE Biloxi-Marine Technology for Our Future: Global and Local Challenges, IEEE. 
Yao Wang, Amir M. Anvar, Amir Parsa Anvar, Eric Hu; A Feasibility Study on Design, Development and Operations of Automated Oceanic Wave Surface Glider Robot

Manley, J \& Willcox S. (2010). "The Wave Glider: A New Concept for Deploying Ocean Instrumentation." Instrumentation \& Measurement Magazine, IEEE 13(6): 8-13.

Manley, J \& Willcox S. (2010). The wave glider: A persistent platform for ocean science. OCEANS 2010 IEEE-Sydney, IEEE.

Manley, JE 2008, Unmanned surface vehicles, 15 years of development. OCEANS (2008). IEEE.

Willcox, S, Manley, J \& Wiggins, S. (2009). "The Wave Glider, an energy harvesting autonomous surface vessel." Sea Technology: 29-31. 